\title{
Low Dielectric Loss Epoxy Polymer Composite from Periwinkle Shell Microparticles
}

\author{
Abdelghaffar Amoka Abdelmalik, ${ }^{*}$ Abdulrahman Sadiq and Umar Sadiq \\ Department of Physics, Ahmadu Bello University, Zaria, 810002, Nigeria \\ *Corresponding author: aaabdelmalik@abu.edu.ng
}

Published online: 25 April 2020

To cite this article: Abdelmalik, A. A., Sadiq, A. \& Sadiq, U. (2020). Low dielectric loss epoxy polymer composite from periwinkle shell microparticles. J. Phys. Sci., 31(1), 1-14. https://doi.org/10.21315/jps2020.31.1.1

To link to this article: https://doi.org/10.21315/jps2020.31.1.1

\begin{abstract}
The quest for improved polymeric insulation to achieve a compact and reliable electrical and electronic power equipment design brings about the idea of composite polymeric insulation. Emphasis has been on chemically synthesised metal oxide nanoparticles. This paper presents the dielectric behaviour of epoxy polymer composite with microparticles with an average particle size of about $4.3 \mu \mathrm{m}$ from the periwinkle shell. The changes in the relative permittivity and dielectric loss of the polymer with the periwinkle shell composite metal oxides at low filler concentrations were studied over a frequency range from $200 \mathrm{~Hz}$ to $100 \mathrm{kHz}$. The results showed that the polymer composite exhibits dielectric characteristics that are quite different when compared with the earlier observed results for polymer micro-composites. Unlike the usual expectations of increasing dielectric loss with increasing filler concentration in polymer micro-composites, the dielectric response of the epoxy-shell microparticle powder composite displayed a decrease in the dielectric loss with micro-filler concentration. The $1 \mathrm{wt} \%$ periwinkle shell microparticle epoxy composite has a dielectric loss lower than that of $0.5 \mathrm{wt} \% \mathrm{Al}_{2} \mathrm{O}_{3}$ nanoparticle epoxy composite. This suggests that the waste periwinkle shell can serve as a cheap resource to produce low-cost polymer composite with improved electrical insulation properties.
\end{abstract}

Keywords: Polymeric insulation, polymer composites, dielectrics, epoxy, dielectric loss

\section{INTRODUCTION}

The quest for improved polymeric insulation brings about the idea of composite dielectrics. This involves the addition of micro/nano-additives in dielectric materials to create composite materials. Composite materials are generally defined as a multiphase material in which the phase distribution and geometry have been 
controlled to optimise one or more properties. The intent of producing composite material is to make a material that combines the best properties. The reported progress in the development of polymer composites with enhanced properties opens the door for the study of more potential composite materials. Several papers have reported progress made in the dispersion of additives in polymers to produce composite dielectric materials. ${ }^{1}$

Polymeric materials are important components of electrical insulation in power equipment and electronic power modules. They are used for insulation in low and medium voltage components such as bus support insulators, enclosures for protective devices, cable accessories, power module encapsulation and others. Polymers have been used as a nonlinear resistive layer at the metallisation edge of power electronic substrates to reduce electric field enhancement at the triple point interface between copper metallisation, a ceramic substrate, and gel or liquid encapsulation. ${ }^{2,3}$ Nanocomposite has been developed from different polymers and nanoparticles and dielectric and partial discharge processes in the processes were studied. Hui et al. studied electrochemical treeing processes in nanocomposite from crossed-linked polyethylene and silica nanoparticle. ${ }^{4}$ Meanwhile, Shah et al. studied the dielectric applications of nanocomposite produced from highdensity polyethylene and clay nanoparticles. ${ }^{5}$ Polyimide is one important class of insulation materials used in microelectronic fabrication. A thin film of polyimide is used to cover the active junction and ring termination of chip diode to shield the metallisation part. In an attempt to improve the insulation properties of polyimide, Wang et al. examined the effect of nano-clay on the properties of polyimide-clay nanocomposite. They concluded that the exhibited low dielectric constant and low dielectric loss by the composite makes the low-cost PI-clay nanocomposites great potentials for microelectronic applications. ${ }^{6}$

The epoxy family is another important class of polymeric insulation and occupies a very important position. Epoxies are a class of thermoset materials used extensively in structural and specialty composite applications because they offer a unique combination of properties that are unattainable with other thermoset resins. Available in a wide variety of physical forms from low viscosity liquid to high melting solids, they are amendable to a wide range of processes and applications. Epoxies offer high strength, low shrinkage, excellent adhesion to various substrates with effective electrical insulation, chemical and solvent resistance, low cost and low toxicity. They are easily cured without the evolution of volatiles or by-products by a broad range of chemical species. Epoxy resins are also chemically compatible with most substrates and tend to wet surfaces easily making them especially wellsuited to the composite application. ${ }^{7}$ 
Dielectric studies have been conducted for epoxy insulation filled with micro, nano and micro-nano particles. Quite many different types of particle have been used as fillers in the epoxy-based polymer. These include silica, carbon nanotubes, oxides of metals, graphene oxide and barium ferrite. ${ }^{8,9}$ It was reported that the dispersion of $\mathrm{TiO}_{2}$ micro-particles in epoxy produced a composite material with relative permittivity and $\tan \delta$ higher than unfilled epoxy. ${ }^{10}$ The addition of $\mathrm{TiO}_{2}$ and $\mathrm{ZnO}$ nanoparticles in epoxy at low loading produced nanocomposite polymer with lower relative permittivity and $\tan \delta$. They were found to have improved the dielectric and mechanical strength of the polymeric insulation. Epoxy nanocomposite systems with inorganic oxide fillers display some advantageous dielectric behaviors at low nanofiller loadings. The permittivity and loss tangent of nanocomposites are found to be lower than that of micro-composites as well as unfilled systems (for low filler loadings). ${ }^{11}$

Synthesised oxides of metals from chemicals and nano-particles from naturally occurring materials such as clays have been used as fillers for epoxy as the base matrix for polymeric insulation. ${ }^{12}$ A well-dispersed epoxy/montmorillonite composite was reported to have displayed low dielectric permittivity, low dielectric loss and enhanced dielectric strength. ${ }^{13}$ However, there are natural sources of metal oxides that exist in nature. These include animal shells which are sources of composite metal oxides. One of these animal shells is the periwinkle shell. It is a byproduct of a class of seafood with calcium oxide as the dominant metal oxide. The earlier report on the characterisation of the shell powder shows that it has a thermal conductivity that is slightly lower than that of $\mathrm{CaO}$. It was also reported that the thermal conductivity is lower than that of $\mathrm{TiO}_{2}$ and $\mathrm{SiO}_{2}$ that are often used to prepare insulating polymer composites. The shell powder has a low dielectric loss and a dielectric constant that is comparable to metal oxide ceramics. ${ }^{14}$ Some synthesised metal oxide nanoparticles and clay nanoparticles were reported to have improved the properties of polymeric insulation. Can particles from the animal shell (waste) similarly produce improved polymer composite for electrical and electronic power insulation? It is on this note that this paper seeks to explore the effect of powder of particle sizes that range from $2 \mu \mathrm{m}$ to $34 \mu \mathrm{m}$ produced from the periwinkle shell on the dielectric properties of the epoxy polymer for power insulation application. 


\section{EXPERIMENTAL}

\subsection{Sample Preparation}

The epoxy resin and a curing hardener were used as the matrix. The filler was obtained from the periwinkle shell, a byproduct of a class of seafood. The powder contained an oxide of metals with $81.8 \%$ of the composition as $\mathrm{CaO}$ and the remaining $18.2 \%$ consists of $\mathrm{MgO}, \mathrm{Al}_{2} \mathrm{O}_{3}, \mathrm{SiO}_{2}, \mathrm{Fe}_{2} \mathrm{O}_{3}, \mathrm{SO}_{3}$, etc. The neat polymer sample was made by mixing the epoxy resin and hardener in the ratio of $3: 1$ respectively in the beaker. The mixture was thoroughly mixed in the beaker with a magnetic stirrer for $10 \mathrm{~min}$. The mixture was then degassed in a vacuum oven at a temperature of $40^{\circ} \mathrm{C}$ for about $8 \mathrm{~min}$. The mixture was transferred into a mould and was pre-cured in the vacuum oven. The pre-cured polymer of thickness $2 \mathrm{~mm}$ was cured at room temperature for $24 \mathrm{~h}$. The same procedure was followed to produce the polymer composite but with the addition of the periwinkle shell powder in the hardener before mixing with the resin. In the preparation of the polymer composite samples, $0.5 \mathrm{wt} \%, 0.6 \mathrm{wt} \%, 0.7 \mathrm{wt} \%, 0.8 \mathrm{wt} \%, 0.9 \mathrm{wt} \%$ and $1 \mathrm{wt} \%$ of the powder was mixed with hardener properly using magnetic stirrer after which it was added to the measured epoxy resin. The prepared samples are described in Table1.

Table 1. Epoxy-periwinkle shell powder micro-composite samples description.

\begin{tabular}{ll}
\hline Code & Sample description \\
\hline Neat epoxy & Epoxy + hardener \\
EPMC1 & Epoxy $+0.5 \mathrm{wt} \%$ periwinkle shell micro-composite \\
EPMC2 & Epoxy $+0.6 \mathrm{wt} \%$ Periwinkle shell micro-composite \\
EPMC3 & Epoxy $+0.7 \mathrm{wt} \%$ periwinkle shell micro-composite \\
EPMC4 & Epoxy $+0.8 \mathrm{wt} \%$ periwinkle shell micro-composite \\
EPMC5 & Epoxy $+0.9 \mathrm{wt} \%$ periwinkle shell micro-composite \\
EPMC6 & Epoxy $+1.0 \mathrm{wt} \%$ periwinkle shell micro-composite \\
\hline
\end{tabular}

\subsection{Surface Morphology and Dispersion of Periwinkle Shell Powder in Epoxy Polymer Composites}

The microstructure of the samples was studied using a Phenom ProX Desktop scanning electron microscope (SEM) equipped with an energy dispersive spectroscopy system. The samples were held on the sample holder using a doublesided carbon tape before putting them inside the sample chamber, and the SEM machine was operated at an accelerating voltage of $15 \mathrm{kV}$, and the image was recorded. 


\subsection{Dielectric Measurement}

The electrical properties of the samples were studied using a programmable LCR Bridge and a two-electrode (stainless steel) test cell. The sample was placed in the test cell connected to the LCR Bridge with applied voltage. The capacitance, resistance and $\tan \delta$ values were recorded within the frequency range of $200 \mathrm{~Hz}$ to $100 \mathrm{kHz}$.

The real part of the relative permittivity (dielectric constant), $\varepsilon^{\prime}$, of the samples was calculated using the expression:

$$
\varepsilon^{\prime}=\mathrm{C} / \mathrm{C}_{\mathrm{o}}
$$

where $\mathrm{C}$ is the capacitance of the samples under test; and $\mathrm{C}_{\mathrm{o}}$ is the capacitance in free space which is expressed as $\mathrm{C}_{0}=\varepsilon_{0} \mathrm{~A} / \mathrm{d}$, where $\varepsilon_{0}$ is permittivity of free space, $A$ is the area and $d$ is the diameter. The imaginary part of the permittivity, $\varepsilon$ ", was then obtained from the expression:

$$
\varepsilon^{\prime \prime}=\tan \delta \cdot \varepsilon^{\prime}
$$

The electrical conductivity, $\sigma$ was then calculated analytically from the formula:

$$
\sigma=\frac{L}{R A}
$$

where $L=0.02 \mathrm{~m}$ (length of sample), $A=$ area of sample and $R=$ resistance of sample.

\section{RESULTS AND DISCUSSION}

The SEM image of some of the polymer samples from the Phenom ProX Desktop SEM equipped with an energy-dispersive spectroscopy system is shown in Figure 1. Figure 1(a) shows the image of the neat epoxy polymer with a magnification of 2000. The image does not display any trace of voids in the polymer. Agglomeration/aggregation of microland nanoparticles in the polymer matrix is common in the preparation of polymer composites. A microscopy image to ascertain the state of the fillers in the composites is very necessary. Figures 1(b and c) show the image of the polymer composites with $0.5 \mathrm{wt} \%$ and $0.7 \mathrm{wt} \%$ periwinkle shell powder respectively. The images show that the particles are well dispersed in the polymer matrix. 

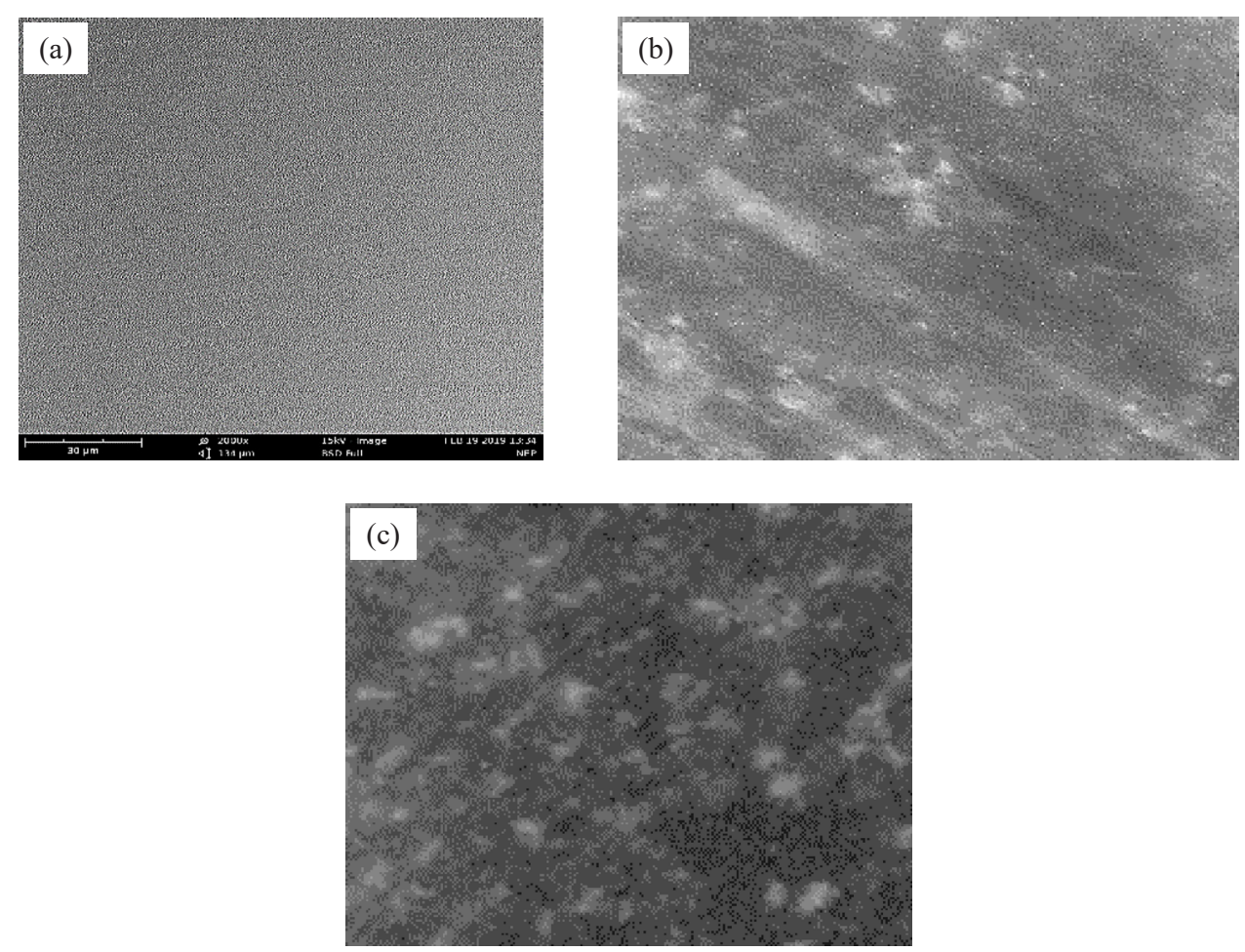

Figure 1: SEM images of magnification 2000X for (a) neat epoxy, (b) epoxy $+0.5 \mathrm{wt} \%$ periwinkle shell powder, and (c) epoxy $+0.7 \mathrm{wt} \%$ periwinkle shell powder.

The real relative permittivity (dielectric constant), imaginary relative permittivity, loss tangent $(\tan \delta)$ and volume conductivity of the samples were obtained within the frequency range of $200 \mathrm{~Hz}$ to $100 \mathrm{kHz}$. The experimental results obtained from the electrical measurement of the prepared seven polymer composite samples are presented in Figures 2 to 4. These include the dielectric constant, imaginary permittivity and loss tangent ( $\tan \delta$ ) of an epoxy polymer composite with $0.5 \mathrm{wt} \%$, $0.6 \mathrm{wt} \%, 0.7 \mathrm{wt} \%, 0.8 \mathrm{wt}^{\mathrm{t}} \%, 0.9 \mathrm{wt} \%$ and $1 \mathrm{wt} \%$ of periwinkle shell powder. The real (dielectric constant) and the imaginary parts of the complex permittivity of the polymer composite samples are shown in Figures 2 and 3.

The real part of the relative permittivity of the polymer composite samples was observed to have decreased from $200 \mathrm{~Hz}$ to $1 \mathrm{kHz}$ and relatively constant from $1 \mathrm{kHz}$ to $70 \mathrm{kHz}$. This constant part is often referred to as the dielectric constant of the samples. The dielectric constant of the neat epoxy is 4.05 from Figure 2. Beyond $70 \mathrm{kHz}$, a sharp increase in real permittivity was observed with an increase in frequency up to $100 \mathrm{kHz}$. Increasing the percentage composition of the powder in the polymer led to an increase in the dielectric constant of the 
samples. The addition of $0.5 \mathrm{wt} \%$ shell powder resulted in an increase of the dielectric constant to about 5.89. Further increase in the percentage concentration of the powder in the polymer shows a more significant increase in the dielectric constant of the polymer composite. The addition of $0.6 \mathrm{wt} \%, 0.7 \mathrm{wt} \%, 0.8 \mathrm{wt} \%$, $0.9 \mathrm{wt} \%$ and $1 \mathrm{wt} \%$ periwinkle shell powder produced an epoxy composite with a dielectric constant of $6.65,7.19,7.53,8.01$ and 8.83 , respectively. A decrease in the imaginary permittivity was observed in Figure 3 for all the samples with an increase in frequency between $200 \mathrm{~Hz}$ and $70 \mathrm{kHz}$ with slopes higher than that of the dielectric constant. Beyond this frequency is also a steep rise in imaginary permittivity. This trend was seen in all samples.

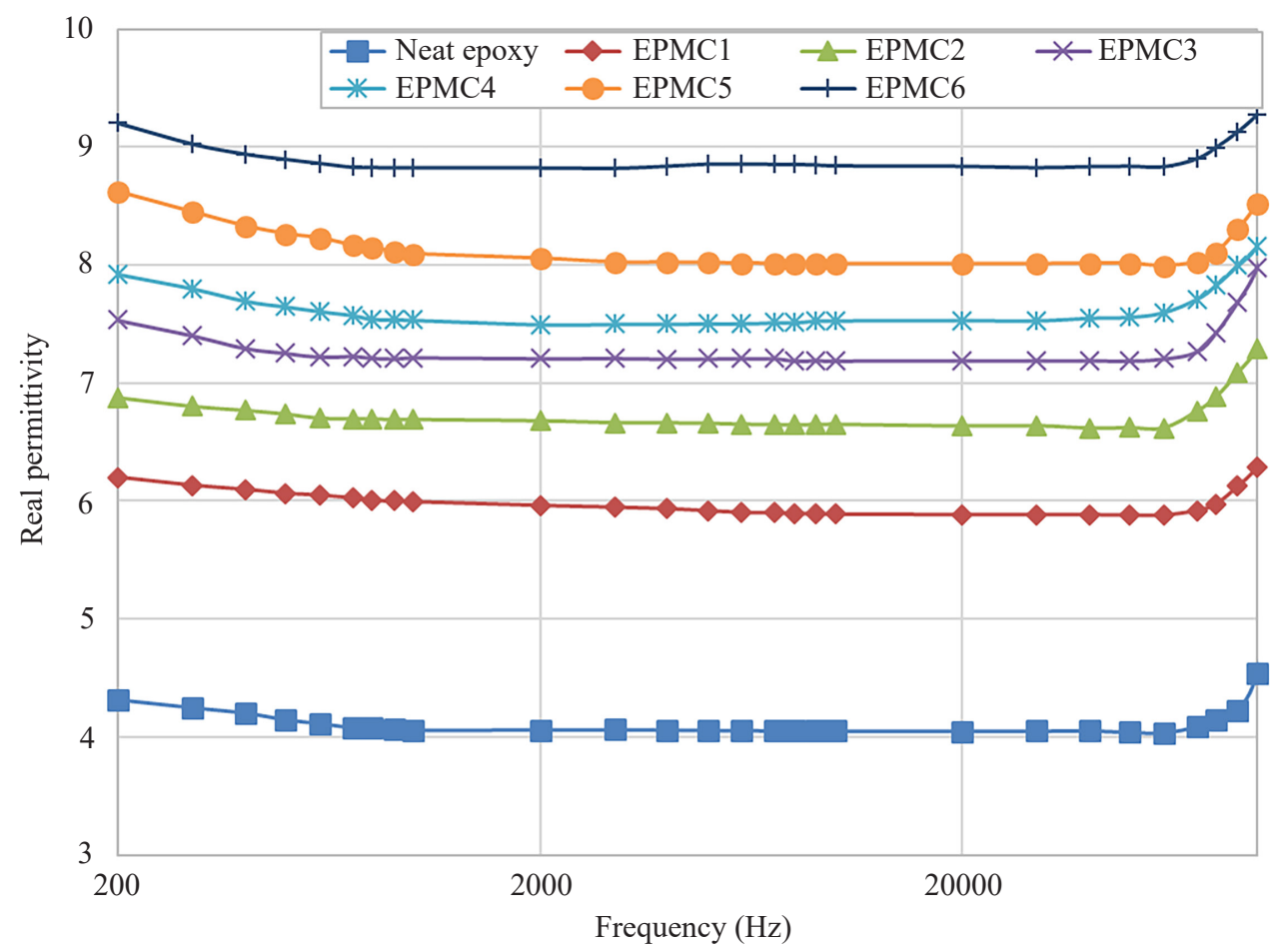

Figure 2: Variation of the dielectric constant of the polymer micro-composite samples as a function of frequency.

An increase in the percentage composition of the powder in the polymer generally results in an increase in the relative permittivity. The dispersion of $0.9 \mathrm{wt} \%$ of the powder in the polymer results in a $0.34 \%$ increase in a dielectric constant while of $1 \mathrm{wt} \%$ of the powder in the polymer results in a $0.77 \%$ increase in the dielectric constant of the polymer composite. The increase in the relative permittivity of the polymer composite is an indication that the dispersion of micro-particle powder in 
epoxy results in an improvement in the charge storage capability of the polymer composite. The increment in the relative permittivity is similar to the earlier reported results where $\mathrm{TiO}_{2}$ micro-particles were dispersed in epoxy. ${ }^{16}$

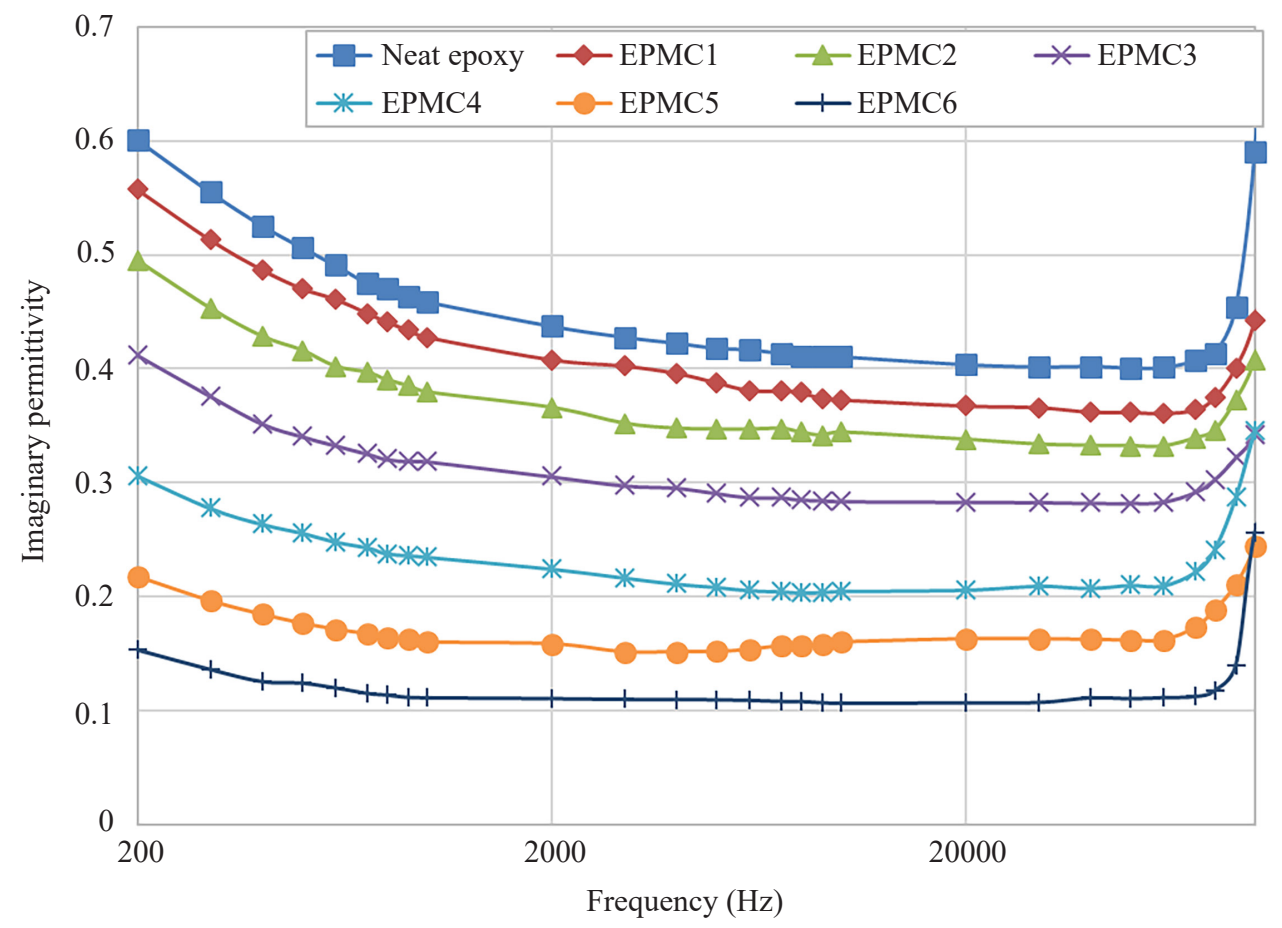

Figure 3: The imaginary permittivity of the polymer micro-composite samples as a function of frequency.

The plot of the loss tangent $(\tan \delta)$ of the polymer composite samples is shown in Figure 4. The dispersion of the powder in the polymer matrix shows a decrease in the imaginary permittivity and a decrease in loss tangent for the studied polymer composite samples. The loss tangent of the epoxy polymer was observed to have decreased by an order of magnitude with the addition of $1 \mathrm{wt} \%$ of periwinkle shell powder. Reduction in charge transport due to the barrier to the charge transport in polymers may have resulted in the reduction in loss tangent. ${ }^{1}$ This may have been due to defects, inter-chain charge transport and transport through interfaces. The presence of a large number of interfaces in the polymer composite and polymer chain entanglements may have also inhibited the motion of charges in the system, thereby causing the lower loss tangent of the samples studied. The loss tangent spectra picked up a slope at low frequency. This could be attributed to interfacial polarisation. This slope was observed to be decreasing with an increase in the percentage of the filler content. 


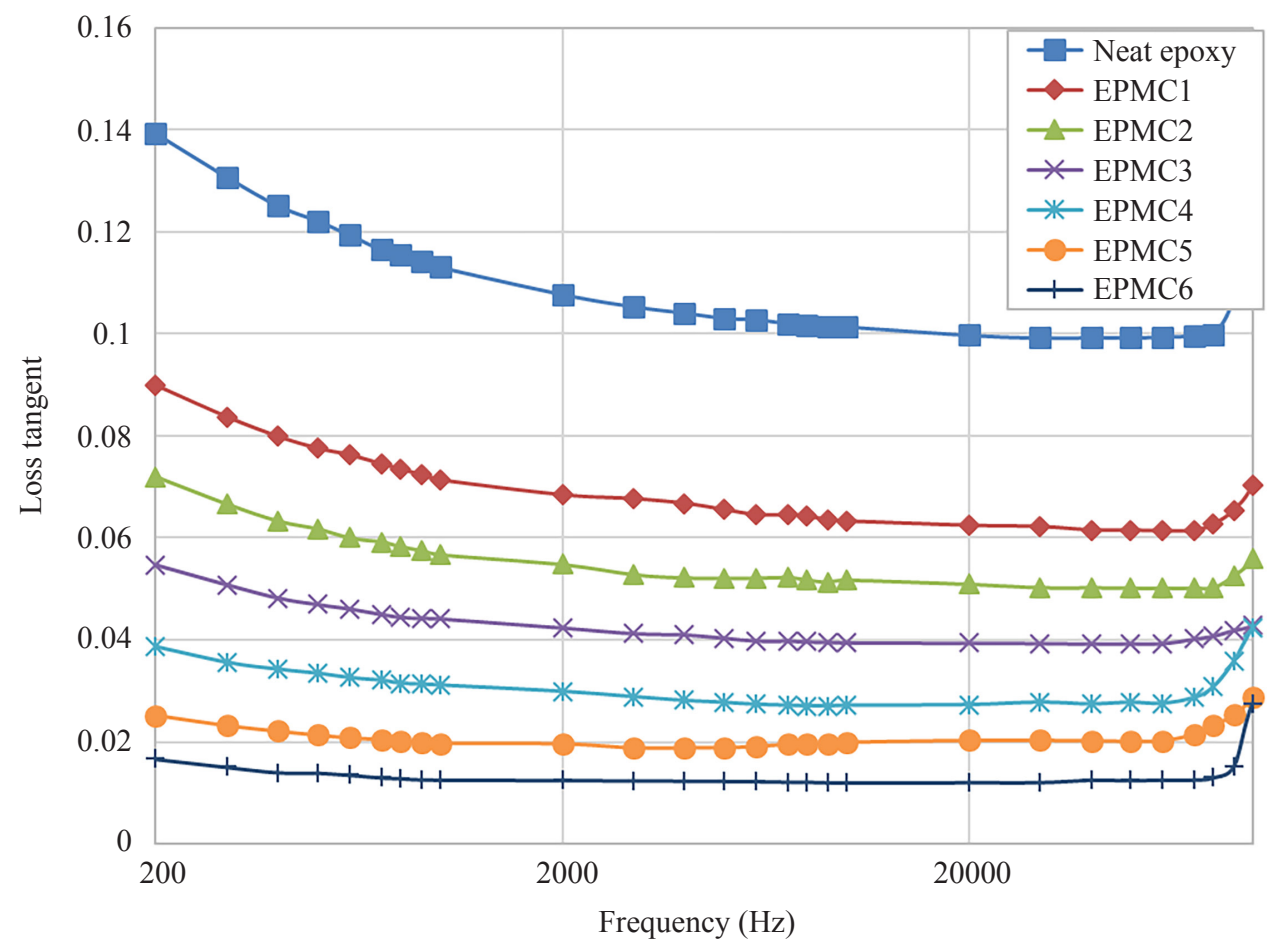

Figure 4: Variation of loss tangent of the composite polymer samples for different percentage of periwinkle shell powder as a function of frequency.

The decrease in the loss tangent due to the addition of the shell powder indicates a reduction in the dielectric loss of the polymer composite. This is contrary to an earlier reported result where the dispersion of $\mathrm{TiO}_{2}$ microparticles in epoxy led to an increase in dielectric loss. ${ }^{14}$ This is an indication that while $\mathrm{TiO}_{2}$ microparticles act as charge carriers in the polymer matrix, the periwinkle shell powder act as a hindrance to charge carriers transfer. A systematic decrease in tan $\delta$ of the polymer composite was observed with an increase in the percentage composition of the periwinkle powder.

A comparison of the obtained loss tangent from epoxy composite with the shell powder and previous report of epoxy composite shows that the $\tan \delta$ value $(0.01201$ at $10^{4} \mathrm{~Hz}$ ) of the epoxy composite with $1 \mathrm{wt} \%$ shell powder is lower than what was reported for epoxy composite with $\mathrm{Al}_{2} \mathrm{O}_{3}$ nanoparticle. Singha and Thomas obtained a tan $\delta$ value of 0.0275 at $10^{8} \mathrm{~Hz}$ for epoxy composite with $0.5 \% \mathrm{Al}_{2} \mathrm{O}_{3}$ nanoparticle, while Kadhim et al. obtained a value of 0.015 at $10^{4} \mathrm{~Hz}$ for epoxy composite with $0.5 \% \mathrm{Al}_{2} \mathrm{O}_{3}$ nanoparticle. ${ }^{16,17}$ 
The occurrence of a (steep) rise in real permittivity, imaginary permittivity and loss tangent at a higher frequency of the dielectric spectra may likely be due to interfacial polarisation. Interfacial or space charge polarisations may have occurred due to the accumulation of space charges at the electrode-sample interface. The interfacial phenomenon is an additional polarisation mechanism apart from ionic, electronic and dipolar mechanisms in a sample. The shell micro-particles have a large volume fraction of interfaces where interfacial polarisation can occur when an electric field of high frequency is applied. Interfacial or space charge polarisations may have also occurred in the samples due to the accumulation of space charges at interface boundaries. The shell microparticles have unmodified surfaces which further enhances the occurrence of interfacial polarisation. Meanwhile, interfacial polarisation at the electrode-sample interface may have likely dominated the polarisation processes at high frequency, thereby shrouding the effect of polarisation due to interface boundaries. The surface treatment of the particles may reduce the interfacial effect.

The volume electrical conductivity of the polymer composite samples measured at $200 \mathrm{~Hz}$ is shown in Table 2 . The table compared the volume conductivity and the AC conductivity at $200 \mathrm{~Hz}$. The AC conductivity was calculated from the expression:

$$
\sigma_{a c}(\omega)=\omega \epsilon_{0} \epsilon^{\prime \prime}(\omega)
$$

where $\omega$ is the angular frequency, $\epsilon_{0}$ is the permittivity of free space and $\epsilon^{\prime \prime}$ is the imaginary permittivity. It was observed from the table that the AC conductivity is three orders of magnitude higher than volume conductivity. This is an indication that polarisation processes dominate electrical conduction in the polymer samples.

Figure 5 displays the log-log plot of the variation of AC electrical conductivity for the neat polymer and composite samples at room temperature and within the frequency range of $200 \mathrm{~Hz}$ and $80 \mathrm{kHz}$. The AC conductivity of all the samples is linearly dependent on the frequency with a slope of 1 . The electrical conductivity decreases with an increase in the percentage composition of the powder. The effective conductivity of the dielectrics is a combination of an $\mathrm{AC}$ and $\mathrm{DC}$ component of the conductivity expressed as: ${ }^{15}$

$$
\sigma(\omega)=\sigma_{0}+\omega \epsilon_{0} \epsilon^{\prime \prime}(\omega)
$$

where $\sigma_{0}$ is the DC conductivity and $\omega \epsilon_{0} \epsilon^{\prime \prime}(\omega)$ is the $\mathrm{AC}$ or loss component. The higher value of the AC conductivity suggests that effective conductivity is dominated by charge transport and dipolar relaxation in the polymer samples and the effective conductivity decreases with an increase in the percentage composition 
of the shell powder. The decrease is due to the scattering of charge carriers in the epoxy, thereby resulting in the reduction of electrical conductivity of the samples. The scattering rate increases with an increase in percentage composition. The result is consistent with the decrease in dielectric loss.

Table 2: Values of electrical conductivities of the samples.

\begin{tabular}{lcc}
\hline Samples & Volume conductivity $\left(\mathrm{S} \mathrm{m}^{-1}\right)$ & AC conductivity $\left(\mathrm{S} \mathrm{m}^{-1}\right)$ \\
\hline Neat epoxy & $9.80379 \times 10^{-12}$ & $6.68677 \times 10^{-9}$ \\
EPMC1 & $5.56342 \times 10^{-12}$ & $6.82666 \times 10^{-9}$ \\
EPMC2 & $3.80773 \times 10^{-12}$ & $5.50588 \times 10^{-9}$ \\
EPMC3 & $2.89487 \times 10^{-12}$ & $4.58705 \times 10^{-9}$ \\
EPMC4 & $2.37312 \times 10^{-12}$ & $3.40711 \times 10^{-9}$ \\
EPMC5 & $2.05419 \times 10^{-12}$ & $2.42048 \times 10^{-9}$ \\
EPMC6 & $1.79266 \times 10^{-12}$ & $1.70475 \times 10^{-9}$ \\
\hline
\end{tabular}

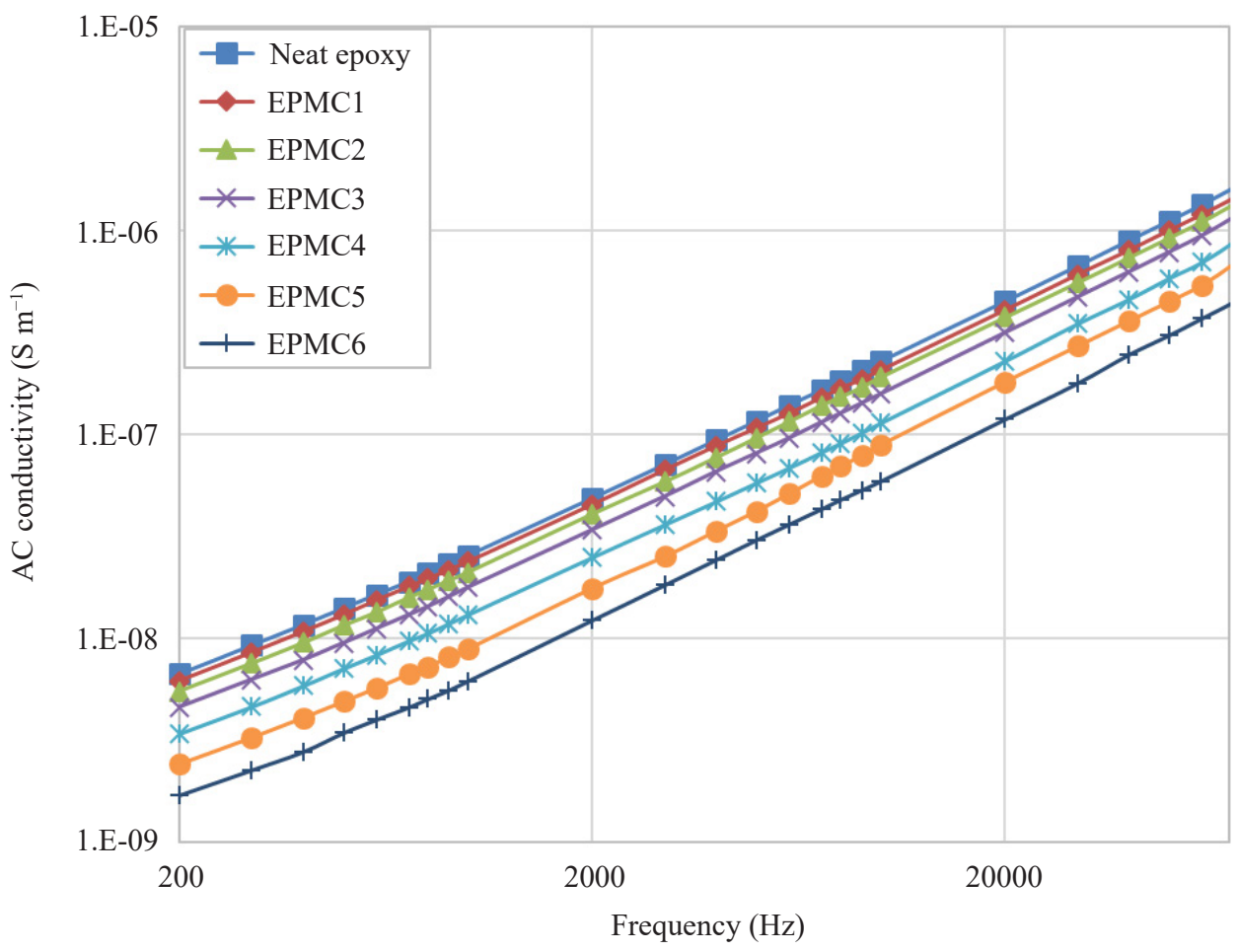

Figure 5: Variation of AC electrical conductivity of the polymer micro-composite sample for different percentages of periwinkle shell powder as a function of frequency. 
Tan $\delta$ can also result from electromagnetic wave absorption by a dielectric material and varies with materials composition. To evaluate the samples' transparency to an electromagnetic wave from the loss tangent data, electromagnetic signal attenuation in the samples was calculated using Equation 6:

$$
\text { Attenuation }=2.3 \cdot f \cdot \tan \delta \cdot \sqrt{\epsilon^{\prime}}
$$

where $f$ is the frequency in $\mathrm{Hz}$ and $\epsilon^{\prime}$ is the relative permittivity. Signal attenuation was then plotted against frequency. The plot displayed a straight line relationship on a log-log plot with a slope of about 1 as shown in Figure 6. The graph has a similar feature with the conductivity plot in Figure 5. Just like the electrical conductivity, signal attenuation decreases with an increase in periwinkle shell particle concentration in the epoxy within the samples studied. This is an indication that the dispersion of particles increases the transparency of the material to the electromagnetic signal. This transparency of the epoxy increases up to the sample with $1 \mathrm{wt} \%$ periwinkle shell particle. The mixing of the materials may have created some conditions that aid the propagation of the electromagnetic wave.

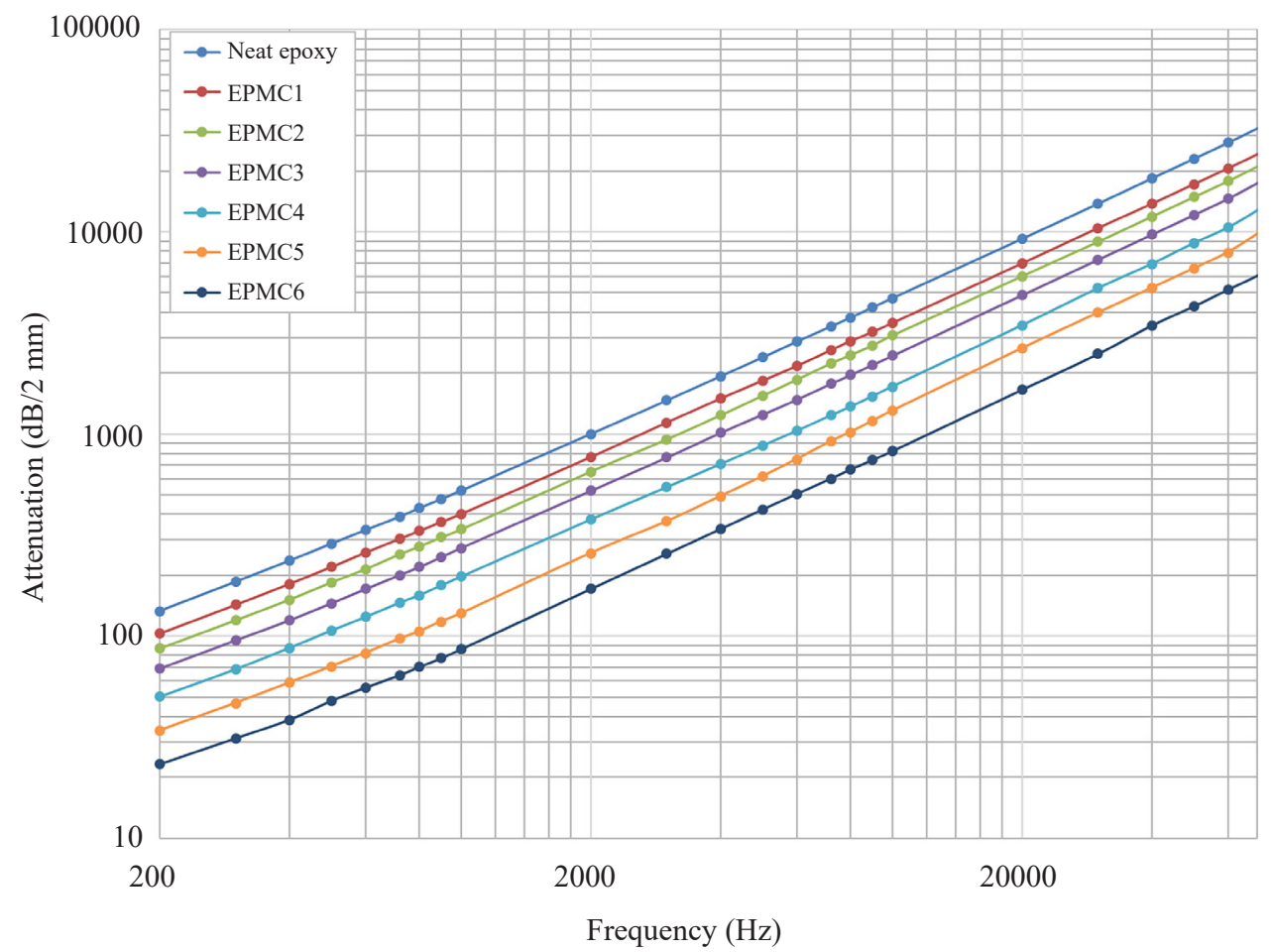

Figure 6: Dielectric absorption due to loss tangent (full-coloured illustration is available in the digital version). 
The whole idea of polymer composite is to produce a material with improved dielectric properties. The results suggest that an epoxy composite with the shell microparticles powder may produce a low loss polymeric insulation compared with the composite with $\mathrm{Al}_{2} \mathrm{O}_{3}$ nanoparticle for electrical/electronic power applications.

\section{CONCLUSION}

The dielectric characteristics of the epoxy composites filled with periwinkle shells were found to exhibit some features different from the usual behaviour of some polymer micro-composites. The dispersion of the fillers from the periwinkle shell in the epoxy matrix increases the relative permittivity of the polymer composites up to $1 \mathrm{wt} \%$, while the loss tangent decreases. The lowering of the composite's dielectric loss is a function of the filler concentration studied. This behaviour may have been due to the intrinsic properties of the dispersed microparticles and the restrictions imposed on the mobility of dipolar groups in the composite system by the interaction of the microparticle and the polymer. The low dielectric loss of $1 \mathrm{wt} \%$ periwinkle shell powder-epoxy composite which is lower than that of $0.5 \mathrm{wt} \% \mathrm{Al}_{2} \mathrm{O}_{3}$ nanoparticle epoxy composite suggests that the polymer composite with improved properties from the waste periwinkle shell is feasible for electrical/ electronic power application. The waste periwinkle shell can serve as a cheap resource to produce low-cost polymer composite with improved insulation properties for use in high voltage applications and encapsulation power electronic modules.

\section{ACKNOWLEDGEMENTS}

The authors wish to acknowledge the support of Mr. Bilyaminu Ibrahim for the laboratory work.

\section{REFERENCES}

1. Nelson, J. K. \& Hu, Y. (2005). Nanocomposite dielectrics-properties and implications. J. Phys. D Appl. Phys., 38, 213-222. https://doi.org/10.1088/00223727/38/2/005

2. Donzel, L. \& Schuderer, J. (2012). Nonlinear resistive electric field control for power electronic modules. IEEE Trans. Dielect. Elect. Ins., 19(3), 955-959. https://doi.org/10.1109/TDEI.2012.6215099

3. Abdelmalik, A. A., Nysveen, A. \& Lundgaard, L. E. (2016). Partial discharges in liquid embedded power electronics: Effects of pressure and liquid nature under negative pulse voltage stress. IEEE Trans. Dielect. Elect. Ins., 23(2), 1119-1125. https://doi.org/10.1109/TDEI.2015.005615 
4. Hui, L. et al. (2009). Electrochemical treeing in XLPE/silica nanocomposites. Paper presented at the 2009 IEEE Conference on Electrical Insulation and Dielectric Phenomena, Virginia, 18-21 October. https://doi.org/10.1109/ CEIDP.2009.5377858

5. Shah, K. S. et al. (2009). High-density polyethylene (HDPE) clay nanocomposite for dielectric applications. IEEE Trans. Dielect. Elect. Insul., 16(3), 853-861. https://doi.org/10.1109/TDEI.2009.5128526

6. Wang, H. W. et al. (2007). Effect of clay on properties of polyimide-clay nanocomposites. J. Appl. Pol. Sci., 318-324. https://doi.org/10.1002/app.25740

7. Boyle, M. A., Martins, C. J. \& Neuener, J. D. (2001). Epoxy resins in composites. In Miracle, D. B. \& Donaldson, S. L. (Eds.), ASM handbook. New York: ASM International, 78-89. https://doi.org/10.31399/asm.hb.v21.a0003362

8. Tuncer, E. et al. (2007). Enhancement of dielectric strength in nanocomposites. Nanotechnol., 18, 325704. https://doi.org/10.1088/0957-4484/18/32/325704

9. Zhang, C. \& Stevens, G. C. (2008). The dielectric response of polar and nonpolar nanodielectrics. IEEE Trans. Dielect. Elect. Insul., 15(2), 606-617. https://doi.org/10.1109/TDEI.2008.4483483

10. Singha, S. \& Thomas, M. J. (2008). Permittivity and tan delta characteristics of epoxy nanocomposites. IEEE Trans. Dielect. Elect. Insul., 15(1), 106-117. https://doi.org/10.1109/T-DEI.2008.4446731

11. Singha, S. \& Thomas, M. J. (2008). Reduction of permittivity in epoxy nanocomposites at low nano-filler loadings. Paper presented at 2008 Annual Report Conference on Electrical Insulation Dialetric Phenomena, 26-29 October, Quebec City, Canada, 726-729.

12. Lan, T. \& Pinnavaia, T. J. (1994). Clay-reinforced epoxy nanocomposites. Chem. Mater., 6, 2216-2219. https://doi.org/10.1021/cm00048a006

13. Zi-Rui, J. et al. (2018). Effects of filler loading and surface modification on electrical and thermal properties of epoxy/montmorillonite composite. Chin. Phys. B, 27(11), 117806. https://doi.org/10.1088/1674-1056/27/11/117806

14. Abdelmalik, A. A. \& Sadiq, A. (2019). Thermal and electrical characterization of composite metal oxides particles from periwinkle shell for dielectric application. SN Appl. Sci., 1, 373. https://doi.org/10.1007/s42452-019-0388-5

15. Von Hippel, A. R. (1954). Theory in dielectric materials and applications. Massachusetts: MIT Press.

16. Singha, S. \& Thomas, M. J. (2008) Dielectric properties of epoxy nanocomposites. IEEE Trans. Dielect. Elect. Ins., 15(1), 12-23. https://doi.org/10.1109/TDEI.2008.4446732

17. Kadhim, M. J. et al. (2014). Dielectric properties of epoxy $/ \mathrm{Al}_{2} \mathrm{O}_{3}$ nanocomposites. Int. J. Appl. Inn. Eng. Manage., 3(1), 468-477. 